\title{
Teacher Retention in a Teacher Resiliency-Building Rural School
}

\author{
William W. Malloy \\ University of North Carolina-Chapel Hill \\ Tawannah Allen \\ Chapel Hill-Carrboro Schools
}

\begin{abstract}
This article focuses on the challenge of teacher retention in rural schools in relation to the No Child Left Behind mandate, that school districts must attract and retain highly qualified teachers. This case study examines the extent to which a rural school enhanced teacher retention by overcoming the barriers that might otherwise have presented a challenge to teacher retention. Findings from this study suggest that the nurturing the nurturers concept, inherent in teacher resiliency-building schools, enhances teacher retention strategies.
\end{abstract}

Controversy continues to swirl over the impact of No Child Left Behind (NCLB) Act 2001(Linn, R. L., Baker, E. L., \& Betebenner, N. W. 2002). One concern relates to the implications of the Act's emphasis on the achievement gap between majority and minority students, which continues to marginalize the minority students. Additionally, there are concerns related to the issue of how high and low wealth school districts will implement certain aspects of the act (i.e., school choice). Perhaps one of the greatest concerns relates to school districts' ability to attract and retain the highly qualified teachers needed to meet the letter of the act. This case study focuses on the latter concern related to successful teacher retention in a rural K-8 teacher resiliencybuilding school in an era of high stakes accountability, in the year 2004 (Carter, 2003).

Most of the focus on resiliency and education has been on developing or sustaining protective factors that impact student resiliency (Henderson \& Milstein, 2003). Resiliency is defined as the ability to bounce back successfully despite exposure to severe risks (Krovetz, 1999). High expectations, meaningful participation, and caring are the most commonly referred to protective factors emerging from resiliency research..

Unfortunately, the student-centered focus of resiliency has overshadowed the importance of teacher resiliency. Thus, although a nurturing school climate has been acknowledged to reduce risk factors in the lives of children; what is far less acknowledged is that creating this climate for students necessitates creating this environment for all school personnel (Bernard, 1993). As Henderson and Milstein (2003) argue, "We need to promote a healthy, selfconfident, effective workforce if we expect educators to be willing and able to support the resiliency needs of students” (p.55).

Because rural districts experience difficulty in recruiting and retaining qualified teachers, scholars have suggested that an ideal recruitment and retention strategy would be to emphasize the benefits of rural schools, benefits such as, attractive class size, genuine personal relationships and a high degree of involvement in the decision making process (Lemke, 1994; Sargent, 2003). What is needed then is the identification of a recruitment and retention plan that contains components that can be readily applied to rural settings. Rosenholtz (1989) summarized the literature and supplied ten essential components of such a plan:

1. carefully selected initial assignments which avoid placing the new teacher in the most difficult schools nor with the most difficult situations

2. opportunities to participate in decision-making, coupled with autonomy in many classroom choices

3. clearly set administrative goals

4. regular, clear feedback and specific suggestions for improvement

5. encouragement from administrators and colleagues

6. a non-threatening environment which encourages questions

7. opportunities for discussion with experienced colleagues

8. encouragement to experiment and discuss the results with colleagues

9. clearly set school rules for student behavior

10. opportunities to interact with parents (Rosenholtz, 1989, pp. 436-437).

There are rural schools and school districts that employ one or more of these strategies to attract and retain teachers. Unfortunately, there appears to be no systematic effort to incorporate these strategies into a coherent plan. Consequently, it is difficult for districts or individual schools to articulate a sustained and coherent effort to maintain the "brightest and best" teachers. What we are suggesting is that a comprehensive retention strategy should employ a resiliency-building focus on nurturing the nurturers' concept (Henderson and Milstein, 2003).

Henderson and Milstein (2003) have developed a sixstep strategy that is needed to develop a resiliency-building school. This strategy is based upon a Resiliency Model (Richardson, Neiger, Jensen, \& Kumpfer, 1990) that suggests that when an individual (adult or child) is confronted with adversity, he or she tends to draw upon protective factors to mitigate that adversity and to enable the individual to move forward. This six-step strategy to foster 
resiliency is divided into mitigating risk and building resiliency.

It has been the intent of the investigators to use the three steps in the building resiliency component to examine the extent to which a K-8 school has established a resiliencybuilding school culture. These steps are: providing caring and support, setting and communicating high expectations and providing opportunities for meaningful participation. The use of this strategy will enable the investigators to describe how one school has developed into a teacher resiliency-building school.

\section{Context}

We selected Nurtureville Elementary for this case study, for three reasons. First, it is located in a rural setting and reflects a student population typical of a rural elementary schooll. In 2004, Nurtureville had 442 students (K-8) and according to Reeves (2003), the average elementary urban school enrolls 634 students, whereas the average elementary rural schools have a population of 400 students. Second, the record of teacher retention at the school is noteworthy. Third, the researchers' awareness of the school's nurturing environment has been noted through the accumulating of anecdotes shared by the principal, superintendent, and other administrators during five years of regular meetings related to professional development school initiatives between the researchers and the district administrators.

The county where Nurtureville is located encompasses 707 square miles and has a population of 52,000. Currently there are 300 residents in Nurtureville and the racial composition is $60 \%$ Caucasian, 35\% African-American, and $5 \%$ other. In recent years there has been an increasing influx of Hispanics and Pakistani residents. The median income for families living in the county is \$42.851. This median income level is heavily influenced by the rather affluent population in the northern portion of the county that consists of high income white collar workers and well-to-do retirees who have relocated from other states.

According to the Fall 2004 Ethnicity/Membership Report, Nurtureville had a student population of 442 students (Caucasian 83\%, African-Americans 10\%, and Hispanic and Other 7\%). The attendance area for the school extends beyond the boundaries of the town of Nurtureville (population 300) because it is an isolated area in the southern portion of the county and also a K-8 school. The poverty level as established through the free and reduced lunch program was 35.3\%. Academically, 44 students were classified as Academically Gifted and 57 students were classified as Exceptional Children.

The professional staff was composed of 1 principal, 1 assistant principal and 31 teachers. Staff ethnicity is $90 \%$ Caucasian, 8\% African-American and 2\% other. All professional staff were certified and reflected the following longevity patterns:(a)1-2 years - 3 ; (b) 3-5 years - 3; (c) 610 years -6 ; (d) 11-15 years -2 ; (e) +15 years -17 .
Regarding the challenges of recruitment and retention that continuously confront rural schools, Nurtureville has been in a very unique position. When there was a teacher opening there were more than a sufficient number of applicants because of the school's reputation for maintaining a safe, engaging, and supportive community for both teachers and students. In addition, one could easily discern from the teacher longevity patterns that once teachers are hired they very seldom leave. Specifically, the teacher turnover rate for 2003-2004 was 6\% as compared to $20 \%$ for the district and $19 \%$ statewide. The 6\% turnover rate was due to one retirement and one resignation related to the relocation of a spouse.

Nurtureville Elementary was accredited by the Southern Association of Colleges and Schools in 1984-1985 and has continued to remain accredited. In fact, according to the North Carolina Department of Public Instruction: Instructional and Accountability Services, since the 2000-01 school year, Nurtureville Elementary has been designated a School of Excellence. A school of excellence is one in which $90 \%$ of the students score at or above grade level in areas of reading, mathematics, science and writing.

Student attendance in 2004 was at 95\%, and discipline referrals indicate that there were only 16 out-of-school suspensions and 119 in-school suspensions. Twenty-six percent of the in-school suspensions were the result of repeat offenders, particularly in grades 6-8..

\section{Method}

We used Merriam's (1998) descriptive case study approach because "it illustrates the complexities of a situation and the fact that not one but many factors may contribute to it” (p. 30). The data reported in this case study were collected between February and May 2004 and focused primarily upon the feedback from the teacher participants.

\section{Participants}

Of the 31 teachers we invited to participate in this study, 28 teachers volunteered to accept.. Three teachers chose not to participate. Twenty-eight teachers responded to the surveys, all of the classrooms of these teachers were observed, and sixteen teachers volunteered to participate in small group interviews structured by a closed questionnaire.

\section{Data Collection}

The general design of this study incorporated the use of archival data review, survey, small group interviews, and observations. We used archival data reviews and an assessment survey developed by Henderson and Milstein (2000) to collect baseline data needed to determine from a professional perspective whether Nurtureville Elementary was a legitimate teacher resiliency-building school.. We used the observations and small group interviews to collect 
data regarding selected barriers to Educator Resiliency, as identified by Milstein and Henry (2000). Our intent was to use these data to demonstrate differences in practices and processes between a traditional versus a teacher resiliencybuilding school.

\section{Archival Data Review and Assessment Survey}

Archival data review. We reviewed data related to student achievement, suspension, and expulsion. Included in this review were demographic data related to students and faculty. In addition we reviewed parent participation rates.

Because this case study focused on teacher retention, we spent a considerable amount of time reviewing school climate survey results, teacher retention rates, and parent program evaluations. We also reviewed memorandums, email, and minutes that pertained to faculty and informal teacher collaborations.

Assessment survey: Henderson and Milstein (2003) suggest that schools may actually be involved in resiliencybuilding strategies for teachers but have not reflected on their efforts using the concept of resiliency as a foundation. Consequently, they encourage schools to collect some baseline data on which they can begin to engage in reflective conversations about the extent to which a school's culture is poised to embrace resiliency-building for teachers. Toward this goal, Henderson and Milstein have developed an instrument to stimulate these reflective conversations. The Likert Scale instrument is called Assessing School Resiliency Building and has 18 items across three dimensions of mitigating risk and 18 items for three dimensions that build resiliency: caring and support, high expectations, and meaningful participation. This case study focuses on the latter three dimensions of resiliency-building, and is limited to 12 of the 18 items that relate specifically to staff perceptions.

Because the authors of this instrument have never had the survey tested for reliability and validity, we felt that its value would be in providing a common language between the researchers and respondents-a language on which to begin to construct the observation protocol and closed questionnaire to capture information regarding the barriers to resiliency.

\section{Observations and Small Group Interviews}

Observations. We used the findings of the assessment survey to establish the extent to which Nurturville was a teacher resiliency-building school. We developed an observation protocol so as to provide data on which to identify practices and processes to demonstrate that Nurtureville had eliminated some of the barriers to teacher resiliency-building and enhance teacher retention. We divided the protocol into the three dimensions of resiliency building: caring and support, high expectations, and meaningful participation.
In addition to classroom observations, we observed faculty and team meetings, teacher planning sessions, teachers' lounge discussions, and informal conversation between teachers and administrators. It was during these observations that we received valuable leads on where important unannounced and informal meetings were to take place. Approximately forty hours were devoted to these types of activities.

Small group interviews: We developed five closed questions to collect data on what Milstein and Henry (2000) have identified as barriers to educator resiliency in the three resiliency building dimensions: caring and support, high expectations, meaningful participation..

These barriers provided the focus of closed questions we constructed, in order to collect data to demonstrate that Nurtureville Elementary instituted practices and processes that enhanced teacher resiliency-building and retention. We developed the following five closed questions related to selected barriers regarding Caring and Support, High Expectations, and Meaningful Participation, as follows:

Caring and Support

- How much focus is given to regular, meaningful, and supportive feedback?

High Expectations

- Do reward systems recognize individual effort?

- What level of effort and output is used to shape group norms?

Meaningful Participation

- Do career opportunities exist for professional growth?

- Are status differences important?

The sixteen teachers who volunteered to participate met in small groups; interviews we structured by the closed questions. There were four group interviews comprised of the sixteen teachers (4 in two separate groups, 6 in one, and 2 in one). We decided to use the group interview technique, so that the teachers could interact with one another in response to the questions. The sessions lasted 30-45 minutes, depending upon the make-up of the group. In three groups there was at least one teacher with no more than three years of experience.

\section{Findings}

The first portion of this section will review the findings from the baseline assessment. This review of findings will provide insight into the extent to which staff perceive the school's maintaining a resiliency building culture for teachers. In the second portion of this section we share the results of the small group interviews using the five closed questions related to barriers to teacher resiliency as the thematic analysis areas.

Assessment findings. The Assessing Resiliency Building survey Likert scale is 1 to 4 , with $1=$ "we have this together,", 2 = "we've done a lot in this area, but could do more," 3 = "we are getting started," and 4 = "nothing has 
been done." The three dimensions of resiliency building examined are caring and support, high expectations, and opportunities for meaningful participation (see Table 1 below).

Table 1

Findings from the Assessing School Resiliency Building Survey

\section{We have this together We've done this but could do more}

\section{Caring and Support}

Dimension 1

\author{
1. Appreciation of staff \\ 2. Recognition of staff \\ 3. Encouragement of staff \\ 4. Fair distribution of resources
}

$\underline{\text { High Expectations }}$
1. Staff believes they will succeed

2. Staff given supportive feedback

3. Staff express "can do" attitude

4. Staff rewarded for risk taking

\section{$\underline{\text { Meaningful Participation }}$}

$78.60 \%$

$42.90 \%$

$89.30 \%$

$84.30 \%$
$21.40 \%$

$57.10 \%$

$10.70 \%$

$10.70 \%$

$\begin{array}{cc}78.60 \% & 21.40 \% \\ 89.30 \% & 7.10 \% \\ 78.60 \% & 21.40 \% \\ 53.60 \% & 25.00 \%\end{array}$
1. Staff engaged in job-specific and organization-wide responsibilities
2. Staff encouraged to do what really matters
3. Staff participation in decision- making

Findings from the Assessing School Resiliency Building survey suggest that in the three dimensions of resiliencybuilding the teachers believe that Nurtureville Elementary is a teacher resiliency-building school.

\section{Discussion}

The findings from the assessing School Resiliency Building survey suggest that Nurtureville Elementary is a resiliency-building school for teaching staff across the three dimensions of resiliency-building. However, the findings from the small group interview related to the barriers to teacher resiliency-building across the three dimensions need closer examination. This examination will focus on the identification of practices and processes that reduce those barriers and distinguish Nurtureville as being different from most elementary schools. Additionally, there needs to be a closer examination of how the three dimensions of teacher resiliency have an impact on teacher retention.

\section{Teacher Resiliency-Building Practices and Processes}

Establishing the fact that Nurtureville as a teacher resiliency-building school requires making a connection between the school's culture and three resiliency -building dimensions. To accomplish this task we used the barriers to educator resiliency-building identified by Milstein and Henry (2000) to highlight practices and processes that Nurtureville Elementary has in place, to reduce or eliminate those barriers across the three dimensions of caring and support, high expectations, and meaningful participation.

Caring and support. In order to identify the practices and processes that reduce the barriers to providing regular and meaningful support and facilitate caring and support at Nurtureville, there needs to be a frame of reference of how these barriers operate in traditional elementary schools. According to Datnow (2000), social and political conditions have driven the push for high stakes accountability in our 
schools. This focus has been a source of great stress for schools that have low physical capital (financial resources, time and materials) as is the case with many isolated rural schools. Low capital schools lean toward strictly adhering to mandated state programs that tend to favor direct instruction (Ascher, 1990; McNeil, 2000). Due to the prescriptive nature of these mandated programs, there is little time for supportive adult-to-adult interactions in other than stressful conditions. In addition, in these situations there are greater opportunities for negative criticism and blame-shifting if the academic performance of students is low or uneven at best. Finally, the teacher evaluation process tends to be shaped by how well teachers embrace the state adopted instructional programs (Achinstein, Ogawa, \& Speighman, 2004).

In contrast to the more traditional schools where the prescriptive nature of accountability leans toward shaping adult-to-adult interactions, Nurtureville elementary tends to view collaboration from a multi-level perspective. Perhaps the best method of identifying practices and processes is to view the resiliency building dimension of caring and support as a system of collaborative relationships. Pugach and Johnson (1995) have identified four dimensions of collaboration: supportive, facilitative, informative, and prescriptive. Supportive collaboration is defined as caring and being available in times of need, joy and stress. Facilitative collaboration promotes the development of capacity through problem solving and dealing independently with professional challenges. The goal of informative collaboration is to provide information to better equip colleagues to address challenges. Prescriptive collaboration is to identify a specified action. Within the teacher resiliency-building context of Nurtureville Elementary, greater emphasis is placed on the supportive, facilitative and informative dimensions.

The supportive dimension was characterized by comprehensive array of formal and informal means of recognition and the "family-like" atmosphere that abounds. Formal support appears in the forms of faculty social gatherings, "dress down days," sunshine fund, reduced assignments when teachers are in stressful situations, released time for personal emergencies, and various teacher recognition strategies (letters of commendation, awards, and public acknowledgements at faculty, school board, and parent meetings. The "family-like" support was related to the informal methods of support from principal and teachers such as personal phone calls in time of stress, regular visits to faculty who are ill, and personal favors related to faculty child care issues.

A major emphasis was placed on the facilitative dimension of collaboration at Nurtureville Elementary. Team teaching, peer evaluations, reflective conversations related to best practices were a few of the aspects of collaboration that enable teachers to develop the capacity to become more effective. These are teacher-led activities that may not be practiced extensively in state mandated instruction programs. The end result is that the feedback teachers receive is more meaningful and supportive because it emerges from teacher initiated activities.

In Nurtureville, the holistic mentoring spirit of school sustains informative collaboration because ninety percent of the teachers have been certified as mentors by the district mentor training program. The faculty decided as a group that it would be beneficial to the entire staff if they were exposed to a standard mentor training program. This exposure would enable them to use a common language that would enhance the transmission of knowledge within the group. The end result of this standard mentoring approach is that the administration was placed in a position of being able to suggest to the new teaching staff to view the entire faculty as mentors, so they could benefit from the expertise of the faculty as a whole. In addition, the faculty used informative collaboration to establish information-sharing networks that were focused on child centered challenges related to program development for special populations (i.e., child abuse, disabilities, uneven attendance patterns and academic achievement disparities). An example of this was the researcher's observation of an information session in which the special education teacher was reviewing how the teaching and behavior modification techniques used in special education could be adapted to general education setting.

Prescriptive collaboration was evident at Nurtureville because of the state mandated accountability program. However the emphasis was not placed on the transmission of knowledge through state mandated instructional programs that tend to rely on lecture and rote learning. To be sure, traditional teaching methods were apparent, but they were used within the orbit of non-traditional strategies related to discovery and constructivist methods that focus on the student as a worker rather than passive recipient. As one teacher indicated, "Of course we must be ever mindful of the state accountability program, but at Nurtureville we encourage one another to make learning fun, and teachers doing all the talking, is boring." Another teacher added, "Our principal says you can't keep students engaged if you stand in front of them all day." Our observations also verified that teachers integrated lecture with other methods of instruction.

When the first three dimensions of collaboration are prevalent, as is the case with Nurtureville Elementary, the prescriptive dimension is still apparent but will not be the sole driving force that promotes adult-to-adult interaction. With less emphasis on prescription, the teacher stress level is significantly reduced.

High expectations. Within this dimension, the focus of the questions was on the following two barriers to high expectations: (a) Do reward systems recognize individual efforts? and (b) What level of output is used to shape group norms? These barriers greatly influence the interaction between student achievement and teaching quality. It has been well documented that there is a definite interface 
between teaching quality and student achievement (DarlingHammond, \& Young, 2002; Ferguson, 1991). Nurtureville Elementary has enhanced this interface by adopting specific philosophies that structure processes and practices that have neutralized effects of these two barriers.

Regarding reward systems and individual effort, the findings clearly suggest that the traditional rewards for Individual (Teacher of the year) and Collective (School of Distinction) efforts are part of the life of Nurtureville. However, this discussion addresses the underlying philosophy that provides the foundation for these rewards. This philosophy encourages the teachers to maintain a collective focus - a focus on the children. This focus eliminates "blaming the victim" issues that frequently enter discussions related to high stakes accountability and student achievement. Every teacher we interviewed in the small groups indicated that they felt responsible for making sure that all students were successes. In fact one teacher articulated the feeling of the teachers by using a time honored cliché: "We believe all children can learn, if given enough time.”

This collective focus on children reduces the teacher isolation that is so prevalent in traditional schools and leads to a highly competitive reward system. In these schools, teachers tended to be responsible for only those students under their tutelage. Consequently the reward systems tended to favor these teachers who had the "best children." At Nurtureville, there are no classes exclusively for the best children so the rewards are for the team effort. Even the Teacher of the Year award is based more on involvement in the life of the school rather than on instructional excellence (Team award).

Perhaps the greatest impact of this collective focus on children is on the teacher's self-esteem. "We help each other to become better so that we can feel better about ourselves," asserted one teacher. Another indicated, "This is serious work, and if one fails, we all fail--and I am not going to let that happen.” Teachers at Nurtureville feel good about what they do at that school and take great pride when parents tell them Nurtureville Elementary is the best school in the county. In essence, the best individual or group reward for teachers at Nurtureville is helping children to become successful.

Regarding group norms and individual output, regarding team effort, in shaping group norms, one teacher indicated "The teachers know what needs to be done around this school to help children succeed and we do it.” Another teacher added "The principal does not have to set the bar for us; we set it along with him." The teachers know what needs to be done at Nurtureville and they collectively establish the norms and monitor the results. They know that if they want to remain a school of distinction, they must continually close the achievement gap while keeping the high achievers motivated. For example, several faculty meetings were devoted to teaching techniques and motivational strategies to keep high performing students engaged. In regard to monitoring the results, this takes place on a weekly basis. If there are instances where it appears that the teacher is not being productive, as one teacher indicated, "If a colleague is not producing, we try to find out why. We do NOT go to the principal.” Establishing the group norms through a collaborative process reinforces the notion that the teachers feel ownership in the directing of the school. As one teacher said, "We create our own stress; we do not let others do it for us."

Meaningful participation. The two barriers for these dimensions were captured with two questions: (a) Do career opportunities exist for professional growth? and; (b) Are status differences important? According to (York-Barr, J., \& Duke, K., 2004) the nature of the teaching position has in the past been one of isolationism and seniority prerogatives that present challenges to teacher leadership. The hierarchical nature of schools tends to diminish the impact of professional growth imperatives and heighten status differences. The Nurtureville Elementary culture fosters positive collaborative relationships and promotes the type of trusting atmosphere that encourages professional growth and obviates status differences.

Regarding career development, the primary reason that there are no barriers to professional growth is that the administration reviews the professional growth plans of each teacher at the beginning and the middle of the school year. The purpose of this review is to ensure that the teachers are exposed to professional development activities that enhance their craft. Additionally, this review provides a forum for the principal and the teachers to discuss the extent to which the teachers seize opportunities to provide leadership in areas of curriculum, instruction, support services, parental engagement, and community development. One senior teacher indicated, “Over the past five years these reviews have continually stimulated my interest to remain involved, rather than counting the time to retirement." As a first year teacher reflected, "I use the review sessions as an opportunity to talk with the principal about how and where my strengths can benefit Nurtureville over time.”

Regarding status differences, the key to reducing the status differences barrier is that teacher seniority does not reign supreme over assignment of classes or availability of leadership opportunities. "All teachers are viewed as equals," according to the principal. What this perception translates into for the teachers is that any one has the potential to lead or offer expertise, depending upon the issue.

\section{Resiliency-Building and Teacher Retention}

Earlier in this report, we suggested that an ideal recruitment and retention strategy for rural schools would be used to emphasize the benefits derived from genuine personal relationships and a high degree of involvement in the decision-making process. Rosenholtz (1989) provided 
more specificity to these benefits by summarizing the literature and identifying ten essential components of a recruitment and retention plan. It is important to examine the findings from this case study of Nurtureville to assess the extent to which the concept of a teacher resiliency building school (Henderson \& Milstein, 2003) embraces Rosenholtz's (1989) essential components related to retention in a coherent fashion.

Table 2

Retention Components: Rosenholtz (1989) and Henderson and Milsteing (2003)

\section{$\underline{\text { Rosenholtz (1989) }}$}

Careful selection of initial assignments

Encouragement from staff

Non-threatening environment, which encourages questions

Opportunities for discussion with experienced colleagues

\section{$\underline{\text { Henderson \& Melstein (2003) }}$}

Caring and Support

Clear administrative goals

High Expectations

Regular feedback

Experimentation encouraged

Clear rules for student behavior

Participation in decision making

Meaningful Participation

\section{Caring and Support}

Under the dimension of caring and support, the teacher resiliency-building culture clearly embraces four of Rosenholtz's essential components. The new teachers enthusiastically expressed support for their teaching assignment from several perspectives. First, they felt that their assignments did not reflect a disproportionate number of children that present social and/or academic challenges. Secondly, the new teachers were most appreciative of the support they received from their colleagues regarding best practices. One new teacher stated, "I never feel overwhelmed because my colleagues have been over the same road and they help me avoid the pitfalls." Third, the leadership style of the administration could be characterized as approachable, accountable, caring, and non-defensive. As one senior teacher stated, "I've never known our new people to be shy about asking questions of the principal."

\section{High Expectations}

There was a sign in the teachers lounge to encourage teachers to: (a) Stick to goals; (b) Accept new challenges and (c) Keep trying. This sign exemplified the spirit of high expectations that pervades the school. What is significant is that this sign was placed there by the teachers-not the administration.

The new teachers were very clear in articulating Nurtureville Elementary's vision for learners. New teacher orientation and staff meetings throughout the year stress the importance of this vision. Those teachers who have been at the school more than five years have indicated that this vision and the accompanying goals have always been articulated and are not a result of the high stakes accountability mandates. The general perception has been that this "eye on prize" focus has been sustained because the vision and goals were not crafted in isolation of faculty, staff, and parental input. Teachers are frequently given feedback from peers and the administration about their practice. The aim of the Nurtureville Elementary teachers is to constantly seek strategies that embrace the learning styles and needs of all the children. This quest requires - even demands - that, the teachers engage in feedback on both previous and current instructional strategies. While observing an impromptu meeting of 3 teachers, the researchers witnessed the teachers reviewing the results of a previously planned unit. When queried about this informal meeting, one teacher replied, "Feedback is an ongoing process and cannot wait for regular meeting times."

In regard to experimentation, the observations and the small group interviews provided ample evidence that the teachers view risk-taking behavior as a normal part of their work day. Perhaps the teacher attitude toward risk-taking 
may be summed by the teacher comment, "I have taught at other places, but I have never felt comfortable with trying new ideas until I got here. In fact, one of the reasons why I was able to encourage a colleague to follow me here was that I told her she would be able to make things happen at Nurtureville."

Students and faculty are all engaged in the identification of rules for student behavior. The evidence of this involvement relates to the low number of referrals for disruptive student behavior and/or student suspensions. To be sure, students get into mischief just as many preadolescents do; the difference is, Nurturville students take responsibility for their actions because they have had input into developing the consequences. Teachers' perceptions of the student body are that they are well mannered children, for the most part, and this fact has enhanced the image of the school. One new teacher stated, "I love coming to school every morning because the students are so nice." Another teacher indicated "I have been here a lot of years and I can honestly say that I have never had a disorderly group of kids. Antsy, yes! Disorderly, no!”

\section{Meaningful Participation}

One of the strongest factors in the retention of Nurtureville Elementary teachers has been the significant level of meaningful participation. Not one individual teacher even inferred that his/her voice could not be heard. Policy formulation and implementation issues can be addressed through the committee and team meeting structure or in individual conferences with the principal. There are some avenues of participation that are voluntary (e.g., planning sessions, site-based committee) and some that are mandatory (e.g., team meetings, accountability updates, and faculty meetings), but no one is over-extended. Another interesting observation is that the amount of meaningful participation increases with years of experience, the thought being that the new teachers need to devote more of their time to classroom responsibilities. Perhaps the most interesting observation was that the majority of the teachers were not interested in pursuing meaningful participation through increased administrative responsibilities. On the contrary,, the teachers appear to enjoy the high level of participation they experience as teachers.

No doubt, many rural schools have elements of the retention plan that Rosenholtz (1989) has identified. However, if these elements have not been purposefully put together in a coherent action plan, the results will be spotty, at best. In isolation, these elements may or may not be effective, because a one-dimensional approach cannot resolve the multi-dimension challenges that are related to teacher retention. What we suggest is needed is that administrators consider the Henderson and Milstein (2003) approach to a teacher resiliency-building school, because it provides a model for organizing all the elements of an effective teacher recruitment and retention plan into three major dimensions of Caring and Support, High Expectations, and Meaningful Participation. A plan organized in this manner addresses the possible barriers to a teacher resiliency-building school and adds a coherent sense of direction on which to build a retention program that can be monitored and systematically evaluated.

In the district in which Nurtureville is located, the school is referred to as a "dream" school, We are proposing that the Henderson and Milstein (2003) approach to teacher resiliency-building be considered as a viable strategy for other rural schools, so that they too can realize the Nurtureville "dream."

\section{References}

Achinstein, B., Ogawa, R.T., \& Speiglman, A. (2004). Are we creating separate and unequal tracks for teachers? The effects of state policy, local conditions, and teacher characteristics on new teacher socialization. American Educational Research Journal, 41(3), 557-603.

Ascher, C. (1990). Testing students in urban schools: Current problems and new directions (Urban Diversity Series No. 100). New York. Eric Clearinghouse on Urban Education.

Bernard, B. (1993). Fostering resiliency in kids: Protective factors in the family, school, and community. San Francisco, CA: West Ed Regional Educational Laboratory.

Carter, C. D. (2003, May). NCLB and the diverse needs of rural schools. It is good for the kids. Retrieved from http://www.ascd.org/cms/index.

Crowther, F., Kaagen, S. S., Ferguson, M., \& Hann, L. (2002). Developing teacher leaders: How teacher leadership enhances school success. Thousand Oaks, CA: Corwin Press.

Darling-Hammond, L., \& Young, P. (2002). Defining "highly qualified teachers": What does "scientificallybased research” tell us? Education Researcher, 31(9), 13-25.

Datnow, A. (2000). Power and politics in the adoption of school reform models. Educational Evaluation and Policy Analysis, 22(4), 357-374.

Desimone, L. (2002). How can comprehensive school reform models be successfully implemented? Review of Educational Research, 12(3), 433-475.

Ferguson, R. F. (1981). Paying for public education: New evidence on how and why money maters. Harvard Journal on Legislation, 28(27), 465-498.

Henderson, N., \& Milstein, M. M. (2003). Resiliency in the schools: Making it happen for students and educators. Thousand Oakes, CA: Corwin

Krovetz, M. L. (1999). Fostering resiliency: Expecting all students to use their minds and hearts well. Thousand Oaks, CA: Corwin. 
Lemke, J. C. (1994). Teacher induction in rural and small districts. In D. Montgomery (Ed.), Rural partnerships: Working together. Proceedings of the Annual National Conference of the American council on Rural Education. Austin, TX: (ERIC Document Reproduction Service, no. ED369589).

Linn, R. L., Baker, E. L. \& Betebenner, N. W. (2002). Accountability systems: Implications of requirements of the no child left behind act of 2001. Educational Researcher, 31(6), 3-16.

McNeil, L. M. (2000). Contradictions of school reform: Educational costs of standardized testing. New York, NY: Routledge.

Merriam, S. B. (1998). Qualitative research and case study applications in education. San Francisco: Jossey-Bass Publishers.

Milstein, M., \& Heny, D. A. (2000). Spreading resiliency. Making it happen for schools and communities.

Thousand Oaks, CA: Corwin.
North Carolina Public School Forum (2001). 2000 local school finance study. Raleigh, NC: Author.

Pugach, M. C., \& Johnson, L. J., (1995). Collaborative practitioners: Collaborative schools. Denver, CO: Love Publishing Company.

Richardson, G. E., Neiger, B. L., Jenson, S., \& Kumpfer, K. L. (1990). The resiliency model. Health Education, 21(6), 33-39.

Rosenholtz, S. J. (1989). Teachers' workplace: The social organization of schools. New York, NY: Longman.

Sargent, B. (2003). Finding good teachers and keeping them. Educational Leadership, 60(8).

York-Barr, J., \& Duke, K. (2004). What do we know about teacher leadership? Findings from two decades of scholarship. Review of Educational Research, 74, 25316. 